\title{
1 SAVED by a toxin: Structure and function of the CRISPR Lon protease.
}

2

3 Christophe Rouillon ${ }^{1,3, *}$, Niels Schneberger ${ }^{1}$, Haotian Chi $^{2}$, Martin F. Peter ${ }^{1}$, Matthias Geyer ${ }^{1}$,

4 Wolfgang Boenigk ${ }^{3}$, Reinhard Seifert ${ }^{3}$, Malcolm F. White ${ }^{2}$, Gregor Hagelueken ${ }^{1, *}$

5

$6{ }^{1}$ Institute of Structural Biology, University of Bonn, Venusberg-Campus 1, 53127 Bonn, 7 Germany

$8{ }^{2}$ School of Biology, University of St Andrews, North Haugh, St Andrews, KY16 9ST, UK.

$9{ }^{3}$ Center of Advanced European Studies and Research (caesar), Ludwig-Erhard-Allee 2, 1053175 Bonn, Germany

11

$12 *$ *Corresponding author emails: back2crispr@gmail.com, hagelueken@uni-bonn.de

13

14 


\section{Summary}

16 CRISPR antiviral defense systems such as the well-known DNA-targeting Cas9- and the more 17 complex RNA-targeting type III systems are widespread in bacteria and archea ${ }^{1,2}$. The type

18 III systems can orchestrate a complex antiviral response that is initiated by the synthesis of 19 cyclic oligoadenylates (cOAs) upon foreign RNA recognition ${ }^{3-5}$. These second messenger 20 molecules bind to the CARF (CRISPR associated Rossmann-fold) domains of dedicated 21 effector proteins that are often DNAses, RNAses, or putative transcription factors ${ }^{6}$. The 22 activated effectors interfere with cellular pathways of the host, inducing cell death or a 23 dormant state of the cell that is better suited to avoid propagation of the viral attack ${ }^{7,8}$. 24 Among a large set of proteins that were predicted to be linked to the type III systems ${ }^{9,10}$, the 25 CRISPR-Lon protein caught our attention. The protein was predicted to be an integral 26 membrane protein containing a SAVED- instead of a CARF-domain as well as a Lon protease 27 effector domain. Here, we report the crystal structure of CRISPR-Lon. The protein is a 28 soluble monomer and indeed contains a SAVED domain that accommodates $\mathrm{CA}_{4}$. Further, we show that CRISPR-Lon forms a stable complex with the $34 \mathrm{kDa}$ CRISPR-T protein. Upon

30 activation by $\mathrm{cA}_{4}$, CRISPR-Lon specifically cleaves CRISRP-T, releasing CRISPR-T 23 , a 23

$31 \mathrm{kDa}$ fragment that is structurally very similar to MazF toxins and is likely a sequence specific 32 nuclease. Our results describe the first cOA activated proteolytic enzyme and provide the first 33 example of a SAVED domain connected to a type III CRISPR defense system. The use of a 34 protease as a means to unleash a fast response against a threat has intriguing parallels to 35 eukaryotic innate immunity. 


\section{$37 \quad$ Main}

38 CRISPR (Clustered Regularly Interspaced Short Palindromic Repeats) is a bacterial and 39 archaeal adaptative immune system that enables microorganisms to fend off attacks by mobile 40 genetic elements such as phages, viruses, or plasmids ${ }^{11}$. The protein complex Cas1-Cas2 captures short DNAs from invaders and integrates them as "memories" into a CRISPR locus 12. Transcripts of these "memories" are processed into small CRISPR RNAs (crRNAs) and integrated into large ribonucleoprotein (RNP) complexes, which can sense the presence of a matching foreign nucleic acid in the cell ${ }^{13}$. Once a foreign nucleotide sequence is detected, an antiviral response is triggered. Depending on the type of CRISPR system ${ }^{1}$, this response can be markedly different, ranging from simple cleavage of the invading nucleic acid by the RNP as in the case of Cas9 ${ }^{14}$, to a complex multipronged defense strategy as found in type III CRISPR systems ${ }^{6}$. For the latter, the Cas 10 subunit of the RNP has a cyclase activity that converts ATP into a recently discovered class of cyclic oligoadenylates (cOAs) upon viral RNA recognition ${ }^{3-5}$. The cOAs are constructed from 3 to 6, 3'-5' linked AMP units ${ }^{15}$ and act as second messengers by binding to proteins harboring a CARF (CRISPR-associated Rossmann-fold) domain ${ }^{16}$. There is a large variety of CARF proteins linked to effector domains with functions ranging from RNA cleavage, supercoiled DNA nicking, dsDNA cleavage to transcription modulation ${ }^{6,17-22}$. The downstream effects of those cOA-activated proteins can lead to an abortive infection or a dormant state of the cell, enabling it to weather the phage attack ${ }^{7,8}$.

Recently, two bioinformatic teams attempted to catalog CARF-domain containing proteins that are likely linked to a functional type III system in bacterial and archaeal genomes ${ }^{9,10}$. Together, the studies revealed more than 100 such proteins, including several membrane proteins and many proteins with currently unknown functions. Another study showed that some of those type III-associated proteins contain a SAVED domain ('SMODS-associated and fused to various effectors domains'; SMODS being the acronym for 'second messenger oligonucleotide or dinucleotide synthetase' ${ }^{23}$ ) instead of CARF, reminiscent of the recently discovered CBASS system ('cyclic-oligonucleotide-based antiphage signaling systems, ${ }^{24}$ ). One of these proteins is CRISPR-Lon (originally termed Lon-CARF), a $60 \mathrm{kDa}$ protein with two predicted transmembrane helices, a Lon-protease domain and a SAVED4 domain ${ }^{25}$.

Here we report the high-resolution crystal structure of the CRISPR-Lon protease from the thermophilic bacterium Sulfurihydrogenibium sp. YO3AOP1. We find that CRISPR-Lon is a soluble monomer and forms a complex with CRISPR-T, a small $34 \mathrm{kDa}$ protein encoded by 
71 CRISPR-T, releasing CRISPR-T 23 , a $23 \mathrm{kDa}$ fragment predicted to have a MazF-like ${ }^{26,27}$ 72 RNAse activity.

73

74

75

76

77

\section{Structure of CRISPR-Lon}

A synthetic, codon-optimized variant of the CRISPR-Lon gene from Sulfurihydrogenibium sp. YO3AOP1 (UNIPROT-ID: B2V8L9) was cloned into the pET11a vector and expressed in E. coli. Although predicted to include two trans-membrane helices ${ }^{9,10}$, we noticed that the protein was found in the soluble fraction of the cell lysate and behaved as a stable monomer during size exclusion chromatography (Supplemental Figure 1 and below). The pure protein readily crystallized, but several rounds of optimization were necessary to obtain well diffracting crystals. No suitable structural model was available at the time, and we prepared a seleno-methionine derivative, which crystallized under the same conditions. The structure of CRISPR-Lon was solved at $2.1 \AA$ by single-wavelength anomalous dispersion phasing and refined to $R / R_{\text {free }}$ values of $19.3 / 22.5$. The electron density was well defined and the model had good geometric parameters (Supplemental Table 1, Supplemental Figure 2) ${ }^{28,29}$. As expected from gel filtration experiments (Supplemental figure 1 and below), the crystal packing does not indicate any stable multimeric forms of CRISPR-Lon (Figure 1A) ${ }^{30}$.

The Lon-protease domain consists of a four-stranded mixed $\beta$-sheet ( $\beta 1-4)$, sandwiched between $\square \mathrm{D}$ of the N-terminal domain and $\square \mathrm{G}, \mathrm{H}, \mathrm{J}$ on the other side. It is structurally related to the ATP-dependent Lon protease from Thermococcus onnorineus (PDB-ID: 3K1J, DALI Z-score: 12.8, Supplemental Figure 3, ${ }^{31}$ ), the ATP-independent VP-4 protease from Tellina virus (3P06, Z-score: 11.0, ${ }^{32}$ ), and the RadA helicase protein from Streptococcus pneumoniae, which lacks the protease active site residues (PDB-ID: 5LKM, Z-score 11.7, ${ }^{33}$ ). In CRISPR-Lon, the catalytic Ser-Lys dyad, a hallmark of Lon proteases, is formed by S152 (loop $\beta 4-\square \mathrm{H}$ ) and K193 ( $\square \mathrm{J}$ ) (Figure 1A). As in other Lon protease structures, a sulfate ion from the crystallization condition binds to the active site entrance (Supplemental Figure 2). The protease active site lies at the end of a narrow channel that presumably binds the substrate peptide (Figure 1B). Supplemental Figure 4A shows a superposition of the Lon-protease domain of CRISPR-Lon with the acyl-enzyme intermediate state of the yellowfin ascites virus ATP-independent Lon protease (PDB-ID: 4IZJ, Z-score: 9.8, ${ }^{34}$ ). In that structure, the substrate peptide attaches to the central $\beta$-sheet as a fifth strand. The corresponding region of CRISPR-Lon, loop $\beta 1 / \beta 2$, is slightly disordered and will likely adopt a similar conformation in the substrate-bound form. The superposition with 4IZJ allowed us to deduce the position of 
104 the P1 site in the protease active site of CRISPR-Lon. As illustrated in Supplemental Figure 4A, only peptides with small side chains such as Ala or Gly would fit into this site.

A
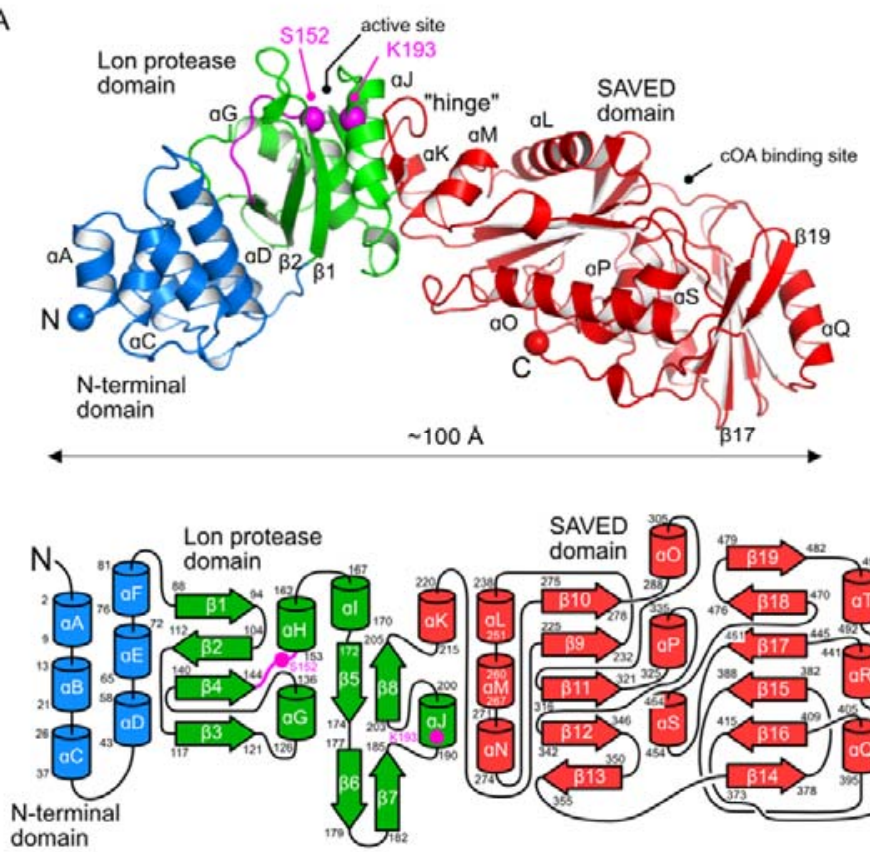

$\sim 100 \mathrm{~A}$
108

109

110

111

112

113

114

115

116

117

118

119

120

121

122

123

124

125

126

127

128

Figure 1: Structure of CRISPR-Lon. A) Overall structure and topology of CRISPR-Lon. The structure is shown as a cartoon model and the individual domains are color-coded as in the topology diagram (bottom). The $\mathrm{N}$ - and C-termini, as well as the protease active site residues, are marked by spheres. The positions of key structural elements are indicated. B) The entrance to the Lon protease active site. The electrostatic surface of the protein is shown with red representing negatively charged and blue representing positively charged areas. The position of the catalytic S152-K193 dyad is indicated and the tentative position of a substrate peptide is indicated by a grey line. C) The cOA binding site with surface electrostatics (blue positive, red - negative). For orientation, selected amino acid residues are labeled.

The C-terminal part of CRISPR-Lon folds into a SAVED4 domain ${ }^{25}$, consisting of two pseudo-symmetric CARF-like domains with a pseudo-two-fold axis running between helices $\square \mathrm{P}$ and $\square \mathrm{S}$ (Figure 1A). Interestingly, the TMHMM 2.0 server predicted that the latter two helices and the directly preceding $\beta$-strands form TM helices or at least membrane associated helices ${ }^{9,35}$ (Figure 1, Supplemental Figure 2B). The SAVED domain forms an extensive cavity on its molecular surface (Figure 1C). Several positively charged residues at the entrance to this pocket presumably bind the phosphate groups of the cOA ligand. By molecular modelling, we found that of $\mathrm{cA}_{3-6}, \mathrm{cA}_{4}$ showed the best steric fit into this pocket (Supplemental Figure 5A). The cOA binding domains of the Cap4, Can1 and Cap5 proteins were identified as close structural homologs using the DALI server (PDB-ID Cap4: 6VM6, Zscore: $17.1,{ }^{24}$; PDB-ID Cap5: 7RWK, Z-score: $9.9^{36}$; PDB-ID Can1: 6SCE, Z-score 8.0, ${ }^{19}$ ). 
129 The superpositions in Supplemental Figure 5 show that despite the low sequence identities 130 (Cap4: 14\%, Can1: 9\%, Cap5: 13\%), the fold of the CARF-like domains is conserved. 131 Interestingly, the position of the effector domain relative to the SAVED- or CARF domains is 132 entirely different between the four structures (Supplemental Figure 5BC). Comparing the 133 cOA binding sites of Cap4 and CRISPR-Lon shows that the surface loops of the SAVED 134 domains lead to a very different shape of the cOA binding site (Supplemental Figure 5AB).

135 The N-terminal domain of CRISPR-Lon forms a bundle of six $\square$-helices ( $\square$ A-F). The 136 DALI server detected structural similarities (Z-score 6.2) to p60-N, the N-terminal protein137 protein interaction domain of Katanin in the p60p80-CAMSAP complex (PDB-ID: 5OW5,

$138{ }^{37}$ ). We noted a surface cluster of hydrophobic residues (W28, L6, V14, L18) formed by $\square$ A-

$139 \mathrm{C}$ as a possible candidate for a protein-protein interaction interface.

\section{CRISPR-Lon is activated by $\mathrm{cA}_{4}$ and specifically cleaves a putative MazF-like toxin}

142 We used the WebFLAGs server ${ }^{38}$ to study the gene neighborhood of CRISPR-Lon homologs 143 and noticed a small 812 bp open reading frame (271 amino acids, $32 \mathrm{kDa}$, UNIPROT-ID:

144 B2V8L8) with no annotated function upstream of the CRISPR-Lon gene (Supplemental 145 Figure 6). We analyzed its sequence with HHPRED ${ }^{39}$ and found homologies to the MazF 146 toxin in the N-terminal half of the protein and weak homologies to DUF2080, a "domain of 147 unknown function" in the C-terminal half (Figure 2A, Supplemental Figure 7A). We 148 predicted the structure with the deepmind/alphafold 2 algorithm ${ }^{40}$. The software produced a 149 model of a two-domain protein with a $\sim 23 \mathrm{kDa}$ - and a $\sim 10 \mathrm{kDa}$ domain connected by an 150 apparently flexible loop (Figure 2B). The structural model was submitted to the DALI server $151^{41}$, revealing structural similarities to MazF-like toxins (Figure 2AB) and various 152 immunoglobulin fold containing proteins (C-terminal fragment, Figure 2AB). Interestingly, 153 the predicted structure appears as a structural mimic of the MazF/E complex with helices $\square \mathrm{A}$, $154 \square \mathrm{D}$, and $\square \mathrm{E}$ blocking the region that binds to the ssRNA target in MazF in a similar fashion 155 to MazE (Supplemental Figure $7 \mathrm{C}^{42}$ ). Helix $\square \mathrm{D}$ of the predicted structure has a large number 156 of arginine and lysine sidechains pointing towards the solvent, suggestive of a nucleic acid 157 interaction interface. We decided to investigate, whether this protein (named "CRISPR-T" 158 below) is the target of the CRISPR-Lon protease. We overexpressed the CRISPR-T gene in $E$. 159 coli and purified it to near homogeneity (Supplemental Figure 8). CRISPR-Lon, CRISPR-T, 160 and different cOAs $(3,4,5,6)$ were mixed at $1: 1: 1.5$ molar ratios and incubated at $60{ }^{\circ} \mathrm{C}$ for 161 one hour. 
A
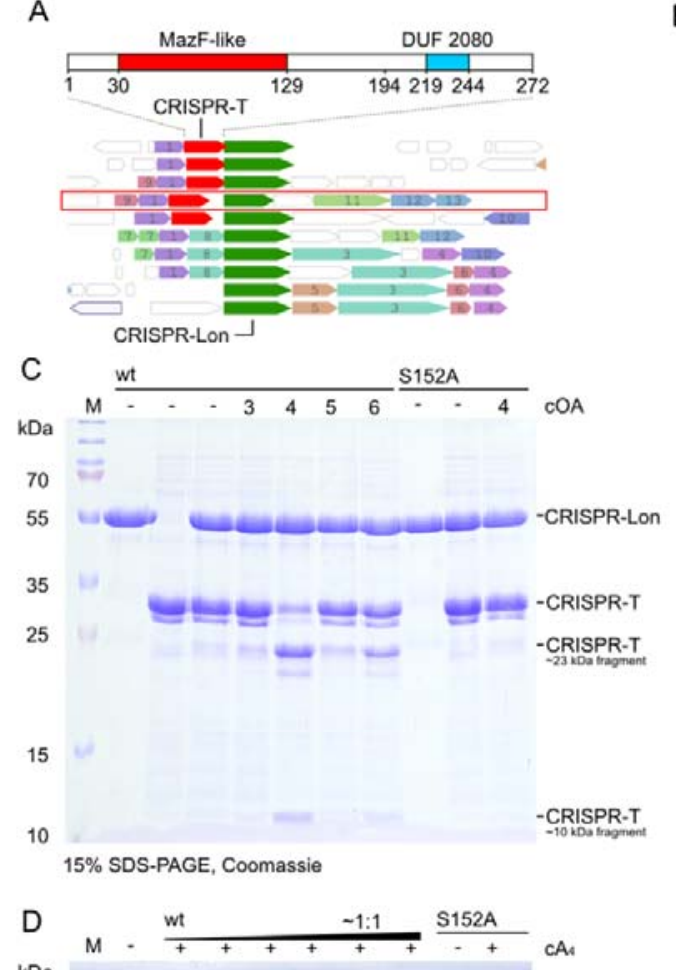

kDa

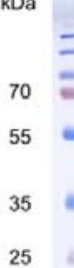

25

15

10
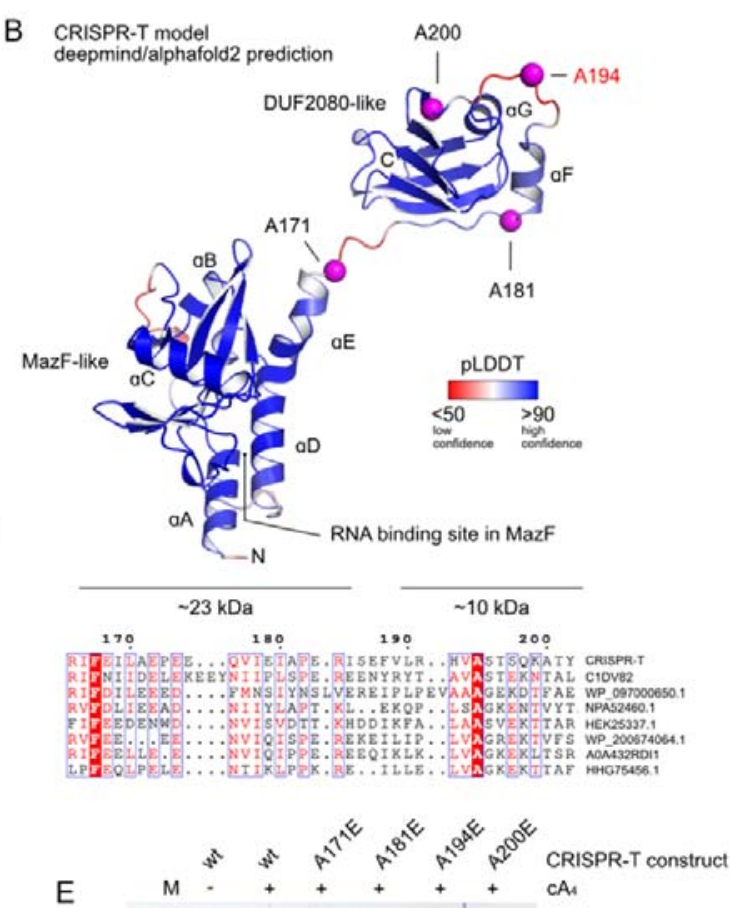

$\mathrm{kDa}$

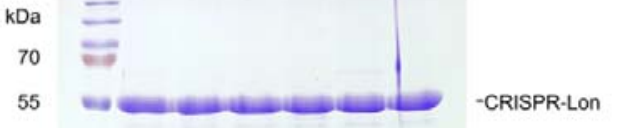

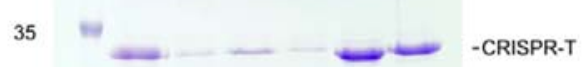

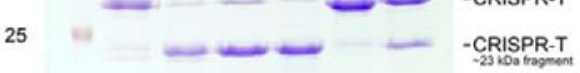

15

10

-CRISPR-T

$12 \%$ SDS-PAGE, Coomassie

$15 \%$ SDS-PAGE, Coomassie

164 Figure 2: CRISPR-Lon is activated by cA4 and cleaves CRISPR-T. A) The WebFLAGs server ${ }^{38}$ was used to investigate the genomic neighborhood of CRISPR-Lon (green). The primary structure of CRISPR-T (red) is shown on top. Regions with homologies found by HH-PRED ${ }^{39}$ are marked. B) A structural prediction (deepmind/alphafold2, ${ }^{40}$ ) of CRISPR-T.

168 The protein is shown as cartoon and colored according to the prediction confidence. The 169 alignment on the bottom ${ }^{58}$ shows that the identified P1 site at A194 is conserved among 170 CRISPR-T homologs. C) SDS-PAGE analysis of CRISPR-Lon induced cleavage of CRISPR171 T. D) Cleavage experiment as shown in C) but using only $\mathrm{CA}_{4}$ and varying concentrations of CRISPR-Lon. E) Mutational analysis of potential CRISPR-Lon cleavage sites in CRISPR-T.

Strikingly, we found that in the presence of $\mathrm{cA}_{4}$, CRISPR-T was indeed cleaved by CRISPRLon. SDS-PAGE analysis revealed two distinct cleavage products with molecular weights of $\sim 23 \mathrm{kDa}$ and $\sim 10 \mathrm{kDa}$ (Figure 2CD). The activity for the other cOAs was significantly lower 
179 Lon, which lacks the nucleophilic serine needed for the peptidase activity. This variant

180 showed no protease activity, proving that indeed, the CRISPR-Lon protease active site was 181 responsible for the observed proteolytic activity (Figure 2C).

182 The peptide sequences of the two cleavage fragments were determined with peptide mass 183 fingerprinting (Supplemental Figure 9). This analysis confirmed that the $\sim 23 \mathrm{kDa}$ (CRISPR$184 \mathrm{~T}_{23}$ ) fragment corresponds to the N-terminal two-thirds of the CRISPR-T protein and the $185 \sim 10 \mathrm{kDa}$ fragment (CRISPR-T ${ }_{10}$ ) to the C-terminal one-third. Based on this result and 186 considering the predicted structure (Figure 2B), we narrowed down the location of the 187 cleavage site to the stretch of residues between amino acids $~ 170-200$ of CRISPR-T. As 188 mentioned above, our CRISPR-Lon structure suggested that only peptides containing an 189 alanine or glycine as the P1 residue will likely fit into the active site of CRISPR-Lon. We 190 created glutamic acid mutants of all four alanine residues in the cleavage region: A171, A181, 191 A194, and A200 (Figure 2B, magenta spheres; the stretch of residues does not contain any 192 glycine). Peptidase assays with all four CRISPR-T mutants were conducted and only the 193 A194E mutation abolished the cleavage completely. Around this position, the amino acid 194 sequence is $\mathrm{N}_{-189} \mathrm{VLRHVA}_{\mathrm{ST}}{ }_{196} \mathrm{C}$, where A194 is very likely the P1 residue (Figure 2E). 195 Notably, A194 is conserved amongst CRISPR-T homologs (Figure 2B, bottom). The peptide 196 fingerprint data in Supplemental Figure 9 also supports this conclusion, as for CRISPR-T 23 , 197 the peptide coverage extents exactly to the identified cleavage site. Thus, the molecular 198 weights of the CRISPR-T cleavage products are $23.0 \mathrm{kDa}$ (N-terminal fragment, CRISPR$\left.199 \mathrm{~T}_{23}\right)$ and $8.7 \mathrm{kDa}$ (C-terminal fragment, CRISPR-T ${ }_{10}$ ), fitting to the sizes observed by SDSPAGE (Figure 2C).

201

CRISPR-Lon and CRISPR-T form a stable complex, releasing a MazF-like toxin upon $\mathrm{cA}_{4}$ induced cleavage

204 We wondered whether CRISPR-Lon and CRISPR-T form a stable complex. To test this, we 205 injected the individual proteins and equimolar mixtures onto a Superose 6 10/300 column 206 connected to a SEC-MALS system (Figure 3A). CRISPR-Lon alone eluted in a single peak at $20717.1 \mathrm{ml}$ corresponding to an experimental molecular weight ( $\mathrm{MW}_{\text {MALS }}$ ) of $52.0 \mathrm{kDa}$, fitting its 208 theoretical molecular weight $\left(\mathrm{MW}_{\text {theor }}\right)$ of $57.7 \mathrm{kDa}$. The CRISPR-T protein eluted at $17.9 \mathrm{ml}$ 209 with an MW $\mathrm{MALS}_{\text {of }} 30.5 \mathrm{kDa}$, also close to the expected value ( $\mathrm{MW}_{\text {theor }} 34.0 \mathrm{kDa}$ ). The 1:1 210 mixture of the two proteins resulted in a single elution peak at $16.2 \mathrm{ml}$. The MW MALS of the 211 complex was $82.4 \mathrm{kDa}$, suggestive of a 1:1 complex of the CRISPR-Lon and CRISPR-T 212 proteins $(52 \mathrm{kDa}+30.5 \mathrm{kDa})$. 

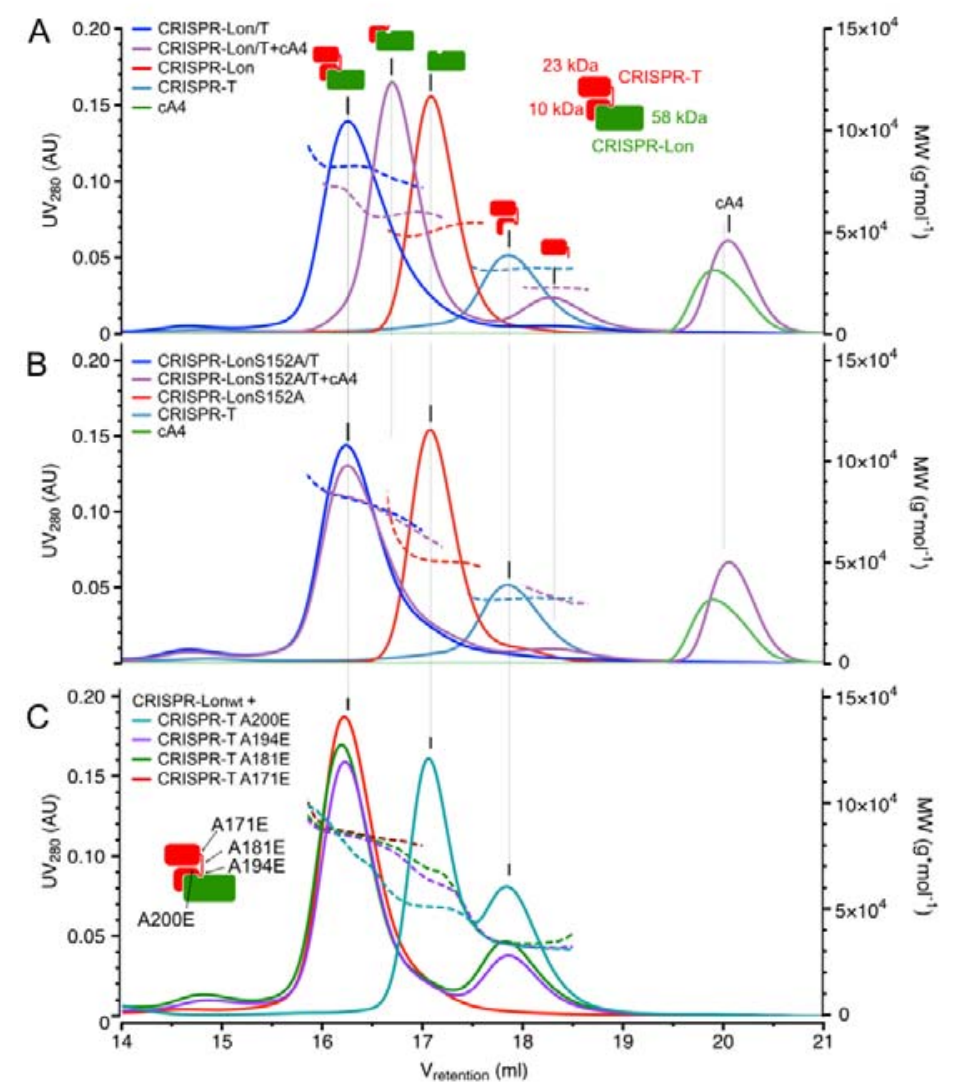

215 Figure 3: CRISPR-Lon forms a 1:1 complex with CRISPR-T. A) SEC-MALS traces

216 (solid lines: $\mathrm{UV}_{280}$, dashed lines: MW $\mathrm{MALS}$ ) of proteolysis reactions with different 217 combinations of CRISPR-Lon wt, CRISPR-T wt, and cOA. The schematic indicates the 218 molecular species behind the individual peaks. B) Same as A) but with CRISPR-Lon ${ }_{\mathrm{S} 152 \mathrm{~A}}$ C) 219 Binding of CRISPR-Lon wt to the indicated CRISPR-T mutants in the absence of $\mathrm{cA}_{4}$. The schematic indicates the position of the mutant in the CRISPR-Lon/T complex.

Next, we repeated the experiment but incubated the CRISPR-Lon/T complex with a slight excess (1:1.1) of $\mathrm{cA}_{4}$ (Figure 3B). The SEC-MALS run showed three elution peaks. The first peak at $16.7 \mathrm{ml}$ with an $\mathrm{MW}_{\text {MALS }}$ of $60.8 \mathrm{kDa}$ nicely agrees with the sum of the MWs of 225 CRISPR-Lon (MW MALS $52.0 \mathrm{kDa})$ plus CRISPR-T $10\left(\mathrm{MW}_{\text {theor }} 8.7 \mathrm{kDa}\right)$. An additional peak at $22618.3 \mathrm{ml}$ with an MW $\mathrm{MALS}_{\text {of }} 21.5 \mathrm{kDa}$ fits the size of CRISPR-T ${ }_{23}\left(\mathrm{MW}_{\text {theor }} 23.0 \mathrm{kDa}\right)$. The $\mathrm{cA}_{4}$ fraction eluted at $20 \mathrm{ml}$ similar to the $\mathrm{cA}_{4}$ control and hence did not bind strongly to the complex. We repeated this set of experiments with the inactive CRISPR-Lon S152A variant. Again, the CRISPR-Lon/T complex was observed but the addition of $\mathrm{cA}_{4}$ did not lead to the observed split into three elution peaks (Figure 3B). Also here, $\mathrm{cA}_{4}$ eluted in a separate peak indicating that the molecule does not bind strongly to the intact CRISPR-Lon/T complex. Finally, we checked whether the four CRISPR-T cleavage-site variants can still form a 
233 complex with CRISPR-Lon (Figure 3C). Whereas A171E, A181E, and the P1 site variant

234 A194E still assembled into a 1:1 complex with the protease, the A200E variant did not. A 235 possible explanation would be that A200 is part of the complex interface. The glutamate at 236 this position would then weaken the interaction, leading to the reduced cleavage efficiency 237 observed in Figure 2E.

238 We proceeded to test for a ribonuclease activity associated with the activated toxin 239 (Supplemental Figure S10). CRISPR-Lon and CRISPR-T were incubated in the presence or 240 absence of activator $\mathrm{cA}_{4}$, and full proteolytic digestion of CRISPR-T was observed after 60 $241 \mathrm{~min}$ at $60{ }^{\circ} \mathrm{C}$ (Supplemental Figure 10A). The cleaved and uncleaved protein mixtures were 242 then incubated with 5 different fluorescent RNA molecules to test a variety of RNA 243 sequences. After $60 \mathrm{~min}$, each oligonucleotide was partially cleaved, generating a 244 characteristic pattern of small bands. However, this activity was not dependent on the 245 presence of the $\mathrm{cA}_{4}$ activator and therefore could not be associated with the activated toxin 246 protein (Supplemental Figure 10B). Using the longest RNA substrate (RNA D), we observed 247 that the Lon protease alone partly degraded the RNA after 60 min incubation at $60{ }^{\circ} \mathrm{C}$, which 248 may reflect a low level of nuclease contamination (Supplemental Figure 10C). In the presence 249 of toxin, the same banding pattern observed in Supplemental Figure S10B was noted. We 250 conclude that the activated toxin does not display specific cleavage activity against any of the 251 five RNAs tested. The most likely explanation is that the toxin is specific for particular 252 nucleic acid species or -structures.

253

\section{Discussion}

255 The CRISPR-Lon protein is an unconventional example of a Lon protease, dedicated to 256 specifically cut a protein and thereby releasing a MazF-like toxin. With a few exceptions such 257 as viral proteases ${ }^{32,34}$, Lon proteases form large homo-hexameric ring-shaped complexes that 258 processively unfold and degrade their targets in an ATP-dependent fashion. They are 259 conserved from prokaryotes to eukaryotes and mitochondria and play essential roles in cell 260 homeostasis, protein quality control, and metabolic regulation ${ }^{43-45}$. CRISPR-Lon integrates 261 the Lon protease domain into a completely different structural scaffold. While CRISPR-Lon is 262 also activated by an ATP analog, it is not a processive enzyme.

263 CRISPR-Lon is the first type III-associated effector protein to be studied biochemically 264 with a SAVED- instead of a CARF domain. The structural similarity with the $\mathrm{cA}_{4}$ binding 265 CARF domains of the CRISPR endonuclease Can1 is striking, particularly given that the 266 sequence similarity is very low. For the latter protein, an integrative approach involving small 
267 angle $\mathrm{X}$-ray scattering revealed that $\mathrm{cA}_{4}$-binding induces large-scale conformational 268 rearrangements of the effector domains that are thought to enable its nuclease activity ${ }^{19}$. It is 269 an interesting structural conundrum how binding of a cOA molecule to the sensor domains 270 can activate effector domains that are connected in entirely different structural ways 271 (Supplemental Figure 5), leading to the question of which mechanism might activate the 272 CRISPR-Lon protease domain upon $\mathrm{cA}_{4}$ binding? For ATP-dependent Lon proteases, a recent 273 study revealed that a conformational transition of an aspartic acid residue located three 274 residues upstream of the catalytic serine is key to the activation mechanism ${ }^{46}$. In the 275 autoinhibited state of such proteases, the side chain forms a salt bridge with the lysine side 276 chain of the catalytic dyad. In CRISPR-Lon, the corresponding residue is a serine, suggesting 277 that the mechanism of activation/autoinhibition is different. Superpositions with other Lon 278 proteases reveal that the helix ( $\square$ J) containing K193 of the catalytic dyad is noticeably 279 shifted, leading to a different relative orientation of the catalytic dyad residues (Supplemental 280 Figure 4B). One might speculate that $\mathrm{cA}_{4}$ binding leads to a structural rearrangement of 281 CRISPR-Lon or even of the whole CRISPR-Lon/T complex that enables the protease activity, 282 releasing the CRISPR-T 23 toxin-like domain. Our efforts to elucidate the function of CRISPR$283 \mathrm{~T}_{23}$ led to the conclusion that it is not an unspecific RNase, suggesting that it cleaves specific 284 rRNA, mRNA or tRNA sequences as observed for other MazF toxins ${ }^{47-49}$. As thought for 285 other cOA dependent effectors, the activity of CRISPR-T might thus help to induce a dormant 286 cell state, avoiding viral propagation and enabling the organism to have enough time to react 287 against the attack ${ }^{7,8}$. If this was indeed true, the preformed CRISPR-Lon/T complex would be 288 reminiscent of a "cocked gun" that could achieve a fast response mechanism, eliminating any 289 delays associated with an upregulation of the toxin combined with the diffusion-limited 290 activation of CRISPR-T by CRISPR-Lon. All organisms harboring CRISPR-Lon on their 291 genomes have the CRISPR-T gene as neighbor. In the vicinity, all genes for CRISPR 292 adaptation (Cas1-2) and interference (type III effector complex of subtype A, B, or D 293 including Cas 10) have been detected but no other CARF proteins such as the RNases Csm6 ${ }^{15}$ 294 or $\mathrm{Csx}{ }^{8}$. The release of a MazF RNase under control of the cOA-activated CRISPR-Lon 295 protease would thus explain how the type III systems in those organisms operate (Figure 4).

296 The use of proteases to trigger defense mechanisms is a well-known scheme in evolution. 297 Prokaryotic type-II toxin-antitoxin (TA) systems, for instance, are activated by degradation of 298 the antitoxin by ATP-dependent Lon proteases ${ }^{50}$. While CRISPR-Lon/T combines the Lon 299 protease fold and its activation by an ATP derivative $\left(\mathrm{cA}_{4}\right)$ in a completely different structural 300 arrangement, the functional scheme appears to be very similar. On the other end of the tree of 
301 life, the innate immune system of higher organisms also employs proteases such as caspases

302 to initiate and amplify fast responses to external threats. Notably, caspase-like peptidases

303 ("Craspases") have also been discovered in connection to type III-D CRISPR systems, 304 although the target of these enzymes is yet undefined ${ }^{51}$.

305

306

307

308

309

310

311

312

313

314

315 Our study provides an interesting glimpse at both the possibilities and current limitations

316 of structure prediction algorithms such as deepmind/alphafold $2{ }^{40}$. CRISPR-Lon was wrongly

317 predicted as a transmembrane protein by algorithms that where state-of-the-art just a short

318 while ago. In contrast, the deepmind/alphafold2 algorithm predicted the structure with

319 astonishing accuracy (Supplemental Figure 2). However, a lot of functionally important

320 information that comes with a high-resolution experimental structure, such as the position of

321 ordered solvent molecules, is missing from the prediction. The second predicted structure,

322 CRISPR-T, is not yet experimentally determined, but the prediction fits very nicely to our

323 biochemical data of protease cleavage. In contrast, the CRISPR-Lon/T complex could not be

324 predicted. Thus, structures of the CRISPR-Lon/T complex, the CRISPR-Lon/cA 4 complex,

325 and the question how the $\mathrm{cA}_{4}$ ligand activates the protease remain interesting and challenging

326 tasks for the classical methods in structural biology. 
bioRxiv preprint doi: https://doi.org/10.1101/2021.12.06.471393; this version posted December 6, 2021. The copyright holder for this preprint (which was not certified by peer review) is the author/funder. All rights reserved. No reuse allowed without permission.

327 


\section{Methods}

\section{Expression and purification of CRISPR-Lon}

330 The codon-optimized gene for CRISPR-Lon was cloned into a pET11a vector with an N331 terminal 10xHis-TEV tag. Site-directed mutagenesis was performed according to a protocol 332 by Liu et al. ${ }^{52}$. All CRISPR-Lon constructs were expressed in lysogeny broth (LB) medium.. 333 E. coli $\mathrm{BL} 21(\mathrm{DE} 3)$ cells were grown at $37^{\circ} \mathrm{C}$ until an $\mathrm{OD}_{600}$ of $0.6-0.8$ was reached. Then, 334 protein expression was started by induction with $0.4 \mathrm{mM}$ IPTG, and the cell suspension was 335 incubated at $30{ }^{\circ} \mathrm{C}$ for $4.5 \mathrm{~h}$ with shaking. Cells were harvested by centrifugation at $4,000 * \mathrm{rcf}$ 336 for $25 \mathrm{~min}$. at $20^{\circ} \mathrm{C}$ and resuspended in lysis buffer ( $20 \mathrm{mM}$ Tris, $50 \mathrm{mM} \mathrm{NaCl}, \mathrm{pH}$ 8.0). The 337 cells were lysed with a sonicator and cell debris was removed by centrifugation at 48,000*rcf 338 for $45 \mathrm{~min}$. at $4{ }^{\circ} \mathrm{C}$. For protein purification, $\mathrm{Ni}^{2+}$-affinity chromatography (20 mM Tris, $33950 \mathrm{mM} \mathrm{NaCl}, \mathrm{pH} 8.0 ; 500 \mathrm{mM}$ imidazole was included for elution) was followed by size340 exclusion chromatography (20 mM Tris, $50 \mathrm{mM} \mathrm{NaCl}, \mathrm{pH}$ 8.0) using a Superdex 200 16/600

341 column. After that, the His-tag was cleaved off by overnight incubation at $4{ }^{\circ} \mathrm{C}$ with a $1: 50$ 342 molar ratio of protein to TEV protease (20 mM Tris, $50 \mathrm{mM} \mathrm{NaCl}, \mathrm{pH} 8.0$ ). A second $\mathrm{Ni}^{2+}$ 343 affinity chromatography was used to remove the TEV protease and uncleaved protein. The 344 purity of the protein was checked by SDS-PAGE after each purification step. After successful 345 purification, the proteins were concentrated, flash-frozen in liquid nitrogen, and stored at $34680^{\circ} \mathrm{C}$ in $20 \mathrm{mM}$ Tris, $50 \mathrm{mM} \mathrm{NaCl}, \mathrm{pH}$ 8.0. The selenomethionine derivative of CRISPR347 Lon was prepared using E. coli B834 cells and the "SelenoMethionine Medium Complete" kit 348 from Molecular Dimensions according to the instructions. Protein expression and purification were done in the same way as for the native protein.

\section{Expression and purification of CRISPR-T}

352 The codon-optimized synthetic gene (BioCat) for CRISPR-T (UNIPROT-ID: B2V8L8), 353 including an N-terminal 10xHis-TEV tag was cloned into a pET11a vector. Protein expression 354 was done using the same expression strain and the same conditions as for CRISPR-Lon. Cells 355 were harvested by centrifugation at $4,000 * \mathrm{rcf}$ for $25 \mathrm{~min}$. at $20^{\circ} \mathrm{C}$ and resuspended in lysis 356 buffer (25 mM Tris, $500 \mathrm{mM} \mathrm{NaCl}, 10 \%$ glycerol, $1 \mathrm{mM}$ DTT, pH 8.0). The cells were lysed 357 with a sonicator and cell debris was removed by centrifugation at $48,000 * \mathrm{rcf}$ for $45 \mathrm{~min}$. at $35820^{\circ} \mathrm{C}$. For protein purification, $\mathrm{Ni}^{2+}$-affinity chromatography $(25 \mathrm{mM}$ Tris, $500 \mathrm{mM} \mathrm{NaCl}$, $3591 \mathrm{mM}$ DTT, $10 \%$ glycerol, pH 8.0; $1 \mathrm{M}$ imidazole was included for elution) was followed by 360 size-exclusion chromatography $(25 \mathrm{mM}$ Tris, $500 \mathrm{mM} \mathrm{NaCl}, 1 \mathrm{mM}$ DTT, $10 \%$ glycerol, 361 pH 8.0) using a Superdex 75 16/600 column. After that, the His-tag was cleaved off by 
362 overnight incubation at $4{ }^{\circ} \mathrm{C}$ with a 1:50 molar ratio of protein to TEV protease $(25 \mathrm{mM}$ Tris,

$363500 \mathrm{mM} \mathrm{NaCl}, 1 \mathrm{mM}$ DTT, $10 \%$ glycerol, $\mathrm{pH}$ 8.0). A second $\mathrm{Ni}^{2+}$-affinity chromatography

364 was used to separate the TEV protease and uncleaved protein. The purity of the protein was

365 checked by SDS-PAGE after each purification step. After successful purification, the proteins

366 were concentrated, flash-frozen in liquid nitrogen, and stored at $-80{ }^{\circ} \mathrm{C}$ in $25 \mathrm{mM}$ Tris,

$367500 \mathrm{mM} \mathrm{NaCl}, 1 \mathrm{mM}$ DTT, $10 \%$ glycerol, $\mathrm{pH}$ 8.0.

368

\section{Protease assay}

370 For protease activity assays CRISPR-Lon and CRISPR-T were used at a final concentration 371 of $\mathrm{c}=4.64 \mu \mathrm{M}$ each. The different cOAs were used at a final concentration of $\mathrm{c}=5.11 \mu \mathrm{M}$.

372 The protein solutions were prepared in $20 \mathrm{mM}$ Tris, $50 \mathrm{mM} \mathrm{NaCl}, \mathrm{pH} 8.0$ and incubated for

$37360 \mathrm{~min}$ at $60{ }^{\circ} \mathrm{C}$. Subsequently, the cOA was added and the mixture was incubated for another

$37460 \mathrm{~min}$ at $60{ }^{\circ} \mathrm{C}$. For SDS-PAGE $3 \mu \mathrm{l}$ of $4 \mathrm{x}$ SDS-loading buffer was added to $9 \mu \mathrm{l}$ of the 375 sample, the mixture was heated for $5 \mathrm{~min}$ at $94{ }^{\circ} \mathrm{C}$ and $10 \mu \mathrm{l}$ were loaded to a $15 \%$ 376 polyacrylamide gel which was run at $250 \mathrm{~V}$ for $40 \mathrm{~min}$.

\section{SEC-MALS}

379 For determination of interactions between CRISPR-Lon and CRISPR-T, SEC-MALS runs 380 were performed on an Agilent 1260 Infinity II Prime Bio LC System coupled with a Wyatt 381 miniDAWN $^{\circledR}$ MALS detector using a Superose6 increase 10/300 chromatography column

382 (GE Healthcare) equilibrated with $25 \mathrm{mM}$ Tris, $500 \mathrm{mM} \mathrm{NaCl}, 1 \mathrm{mM}$ DTT, $10 \%$ glycerol, 383 pH 8.0. Data acquisition and evaluation were carried out using ASTRA 8 software (Wyatt 384 Technologies). The flow rate was set to $0.5 \mathrm{ml}^{*} \mathrm{~min}^{-1}$ and an injection volume of $50 \mu 1$ was 385 used for the experiments. Final concentrations were set to $\mathrm{c}(\mathrm{CRISPR}-\mathrm{Lon})=51 \mu \mathrm{mol}^{*} \mathrm{l}^{-1}$, $386 \mathrm{c}($ CRISPR-T $)=51 \mu \mathrm{mol}^{*} \mathrm{l}^{-1}$, and $\mathrm{c}(\mathrm{cA} 4)=60 \mu \mathrm{mol} * \mathrm{l}^{-1}$ by dilution with $25 \mathrm{mM}$ Tris, $500 \mathrm{mM}$ $387 \mathrm{NaCl}, 1 \mathrm{mM}$ DTT, $10 \%$ glycerol, $\mathrm{pH} 8.0$.

\section{Mass spectrometry}

390 Gel bands were cut from SDS-PAGE gels and sent to the Mass Spectrometry and Proteomics 391 Facility of the University of St Andrews for analysis (https://mass-spec.wp.st-andrews.ac.uk).

\section{Ribonuclease assay}

394 Ribonuclease activity of cleaved CRISPR-T (23 kDa fragment) was assayed by incubating 395 full-length CRISPR-T with CRISPR-Lon and five different fluorescent-labelled RNA 
396 substrates, which were synthesised with the fluorescent dye (6-FAM) attached at 5' end

397 (purchased from Integrated DNA Technologies (IDT), Supplemental Table 2). The mixture of

398 CRISPR-Lon $(5.5 \mu \mathrm{M})$ and CRISPR-T $(5.0 \mu \mathrm{M})$ was incubated at $60^{\circ} \mathrm{C}$ in $20 \mathrm{mM}$ Tris-HCl,

$399 \mathrm{pH} 8.0,50 \mathrm{mM} \mathrm{NaCl}$ and $0.5 \mathrm{mM}$ EDTA for $30 \mathrm{~min}, \mathrm{cA}_{4}(7.6 \mu \mathrm{M})$ was then added and the

400 mixture was incubated for another $30 \mathrm{~min}$ at $60{ }^{\circ} \mathrm{C}$, followed by adding one of the above

401 RNA substrates into the mixture, incubating for an additional $60 \mathrm{~min}$ at $60^{\circ} \mathrm{C}$. Finally, $6 \mu \mathrm{l}$ of

402 the sample was analysed on SDS-PAGE (NuPAGE Bis-Tris Gel, Thermo Fisher Scientific)

403 by heating at $95^{\circ} \mathrm{C}$ for 5 min with $2 \mu \mathrm{L}$ of SDS-PAGE loading dye (Thermo Fisher Scientific;

404 NuPAGE Sample Reducing Agent and LDS Sample Buffer). The remaining $14 \mu 1$ of the

405 sample were loaded to $20 \%$ acrylamide, $7 \mathrm{M}$ urea, $1 \times \mathrm{TBE}$ denaturing gel, which was run at

$40630 \mathrm{~W}, 45^{\circ} \mathrm{C}$ for $2 \mathrm{~h}$. The gel was finally imaged by Typhoon FLA 7000 imager (GE

407 Healthcare) at a wavelength of $532 \mathrm{~nm}$ (pmt 600 700).

408

409 X-ray crystallography

410 Pure CRISPR-Lon protein was concentrated to $20 \mathrm{mg} / \mathrm{ml}$ and crystallized using a Gryphon 411 pipetting robot (Art Robbins) and commercial crystallization screens (Molecular

412 Dimensions). Hexagonal crystals appeared after one day in condition D7 of the JCSG+ 413 screen. Several rounds of optimization were performed to achieve well-diffracting crystals.

414 The final crystallization condition was $0.1 \mathrm{M}$ Tris-Cl pH 8.0, 38.8 \% PEG 400, 0.29 M $415 \mathrm{Li}_{2} \mathrm{SO}_{4}$. The SeMet derivative (see above) was crystallized under similar conditions and 416 yielded identical crystals. The crystals were harvested without further cryo-protection and a 417 diffraction dataset was recorded at beamline P13 operated by EMBL Hamburg at the PETRA 418 III storage ring (DESY, Hamburg, Germany) ${ }^{53}$. The diffraction data were automatically 419 processed with XDS ${ }^{54}$. The structure was solved using phenix.autosolve and refined with 420 phenix.refine ${ }^{55}$. Model building was performed in Coot ${ }^{56}$ and figures were prepared with 421 PyMOL (www.pymol.org). The geometry of the model was checked with MolProbity ${ }^{57}$.

422

\section{Structural predictions with deepmind/alphafold2}

424 The source code of the deepmind/alphafold2 algorithm was downloaded from 425 https://github.com/deepmind/alphafold and installed as described 426 https://github.com/deepmind/alphafold. The algorithm was run using the CASP14 preset. The 427 pLDDTs scores were extracted and mapped onto the structures with PyMOL. The CRISPR428 Lon/T complex was predicted by concatenating the CRISPR-T and CRISPR-Lon amino acid 429 sequencing separated by a 30 amino acid linker consisting of "U" residues ("unkown"). 


\section{Data availability statement}

432 The crystal structure has been deposited in the PDB (XXXX).

433

\section{Code availability statement}

435 No custom code was used in this work.

\section{Acknowledgements}

438 The synchrotron MX data were collected at beamline P13, operated by EMBL Hamburg at the 439 PETRA III storage ring (DESY, Hamburg, Germany). We would like to thank Gleb 440 Bourenkov and Isabel Bento for the assistance in using the beamline. We thank Virginius 441 Siksnys for helpful discussions. We thank Sally Shirran for the mass spectrometry analysis.

442 We would like to thank Norbert Brenner for technical assistance.

\section{Author contributions}

445 C.R. and G.H. conceived and supervised the study and performed initial protein expression 446 and crystallization experiments. N.S., C.R., and G.H. designed experiments. N.S. optimized 447 the purification of CRISPR-Lon and CRISPR-T, crystallized CRISPR-Lon and established 448 and performed the cleavage assays and SEC-MALS experiments. M.F.P. cloned the cleavage 449 site mutants. G.H. and N.S. solved and refined the CRISPR-Lon structure. H.C. and M.F.W. 450 planned and performed the ribonuclease assay. C.R., M.F.W., H.C., N.S., and G.H. analyzed 451 the data and wrote the paper. R.S. and W.B. cloned the initial CRISPR-Lon construct. All 452 authors discussed the results and commented on the manuscript at all stages. 


\section{References}

455 1. Makarova, K. S., Wolf, Y. I. \& Koonin, E. V. Classification and nomenclature of

456 CRISPR-Cas systems: where from here. The CRISPR Journal 1, 325-336 (2018).

457 2. Zhu, Y., Klompe, S. E., Vlot, M., van der Oost, J. \& Staals, R. H. J. Shooting the messenger: RNA-targetting CRISPR-Cas systems. Bioscience reports 38, BSR20170788 (2018).

3. Kazlauskiene, M., Kostiuk, G., Venclovas, Č., Tamulaitis, G. \& Siksnys, V. A cyclic oligonucleotide signaling pathway in type III CRISPR-Cas systems. Science 357, 605609 (2017).

4. Niewoehner, O. et al. Type III CRISPR-Cas systems produce cyclic oligoadenylate second messengers. Nature 548, 543-548 (2017).

5. Rouillon, C., Athukoralage, J. S., Graham, S., Grüschow, S. \& White, M. F. Control of cyclic oligoadenylate synthesis in a type III CRISPR system. Elife 7, e36734 (2018).

6. Athukoralage, J. S. \& White, M. F. Cyclic oligoadenylate signalling and regulation by ring nucleases during type III CRISPR defence. RNA rna.078739.121 (2021).

7. Meeske, A. J., Nakandakari-Higa, S. \& Marraffini, L. A. Cas13-induced cellular dormancy prevents the rise of CRISPR-resistant bacteriophage. Nature 570, 241-245 (2019).

8. Rostøl, J. T. et al. The Card 1 nuclease provides defence during type III CRISPR immunity. Nature 590, 624-629 (2021).

9. Shmakov, S. A., Makarova, K. S., Wolf, Y. I., Severinov, K. V. \& Koonin, E. V. Systematic prediction of genes functionally linked to CRISPR-Cas systems by gene neighborhood analysis. Proc Natl Acad Sci U S A 115, E5307-E5316 (2018).

10. Shah, S. A. et al. Comprehensive search for accessory proteins encoded with archaeal and bacterial type III CRISPR-cas gene cassettes reveals 39 new cas gene families. RNA Biol 16, 530-542 (2019).

11. Gasiunas, G., Sinkunas, T. \& Siksnys, V. Molecular mechanisms of CRISPR-mediated microbial immunity. Cell Mol Life Sci 71, 449-465 (2014).

12. Sasnauskas, G. \& Siksnys, V. CRISPR adaptation from a structural perspective. Curr Opin Struct Biol 65, 17-25 (2020).

13. Jiang, F. \& Doudna, J. A. CRISPR-Cas9 Structures and Mechanisms. Annual Review of Biophysics 46, 505-529 (2017).

14. Jinek, M. et al. A programmable dual-RNA-guided DNA endonuclease in adaptive bacterial immunity. Science 337, 816-821 (2012).

15. Jia, N., Jones, R., Sukenick, G. \& Patel, D. J. Second messenger cA4 formation within the composite Csm1 Palm pocket of type III-A CRISPR-Cas Csm complex and its release path. Molecular cell 75, 933-943. e6 (2019).

16. Makarova, K. S., Anantharaman, V., Grishin, N. V., Koonin, E. V. \& Aravind, L. CARF and WYL domains: ligand-binding regulators of prokaryotic defense systems. Frontiers in genetics 5, 102 (2014).

17. Lau, R. K. et al. Structure and mechanism of a cyclic trinucleotide-activated bacterial endonuclease mediating bacteriophage immunity. Molecular cell 77, 723-733. e6 (2020).

18. Lintner, N. G. et al. The structure of the CRISPR-associated protein Csa3 provides insight into the regulation of the CRISPR/Cas system. Journal of molecular biology 405, 939-955 (2011).

19. McMahon, S. A. et al. Structure and mechanism of a Type III CRISPR defence DNA nuclease activated by cyclic oligoadenylate. Nat Commun 11, 500 (2020).

20. Rostøl, J. T. et al. The Card 1 nuclease provides defence during type III CRISPR immunity. Nature 590, 624-629 (2021). 
21. Garcia-Doval, C. et al. Activation and self-inactivation mechanisms of the cyclic oligoadenylate-dependent CRISPR ribonuclease Csm6. Nature communications 11, 1-9 (2020).

22. Lawrence, C. M., Charbonneau, A. \& Gauvin, C. Cyclic Tetra $\square$ Adenylate (cA4) Activates CRISPR Associated Transcription Factor Csa3, Providing Feedback Activation of Protospacer Acquisition and crRNA Expression. The FASEB Journal 34, 1-1 (2020).

23. Burroughs, A. M., Zhang, D., Schäffer, D. E., Iyer, L. M. \& Aravind, L. Comparative genomic analyses reveal a vast, novel network of nucleotide-centric systems in biological conflicts, immunity and signaling. Nucleic Acids Res 43, 10633-10654 (2015).

24. Lowey, B. et al. CBASS Immunity Uses CARF-Related Effectors to Sense 3'-5' - and 2'-5'-Linked Cyclic Oligonucleotide Signals and Protect Bacteria from Phage Infection. Cell 182, 38-49.e17 (2020).

25. Makarova, K. S. et al. Evolutionary and functional classification of the CARF domain superfamily, key sensors in prokaryotic antivirus defense. Nucleic acids research $\mathbf{4 8}$, 8828-8847 (2020).

26. Amitai, S., Yassin, Y. \& Engelberg-Kulka, H. MazF-mediated cell death in Escherichia coli: a point of no return. $J$ Bacteriol 186, 8295-8300 (2004).

27. Zhang, Y. et al. MazF cleaves cellular mRNAs specifically at ACA to block protein synthesis in Escherichia coli. Mol Cell 12, 913-923 (2003).

28. Zwart, P. H. et al. Automated structure solution with the PHENIX suite. Methods in Molecular Biology (Clifton, N.J.) 426, 419-435 (2008).

29. Chen, V. B. et al. MolProbity: all-atom structure validation for macromolecular crystallography. Acta Crystallographica Section D 66, 12-21 (2010).

30. Krissinel, E. Crystal contacts as natures docking solutions. Journal of computational chemistry 31, 133-143 (2010).

31. Cha, S. S. et al. Crystal structure of Lon protease: molecular architecture of gated entry to a sequestered degradation chamber. EMBO J 29, 3520-3530 (2010).

32. Chung, I. Y. \& Paetzel, M. Crystal structure of a viral protease intramolecular acylenzyme complex: insights into cis-cleavage at the VP4/VP3 junction of Tellina birnavirus. J Biol Chem 286, 12475-12482 (2011).

33. Marie, L. et al. Bacterial RadA is a DnaB-type helicase interacting with RecA to promote bidirectional D-loop extension. Nat Commun 8, 15638 (2017).

34. Chung, I. Y. \& Paetzel, M. Crystal structures of yellowtail ascites virus VP4 protease: trapping an internal cleavage site trans acyl-enzyme complex in a native Ser/Lys dyad active site. J Biol Chem 288, 13068-13081 (2013).

35. Krogh, A., Larsson, B., von Heijne, G. \& Sonnhammer, E. L. L. Predicting transmembrane protein topology with a hidden markov model: application to complete genomes. Journal of Molecular Biology 305, 567-580 (2001).

36. Fatma, S., Chakravarti, A., Zeng, X. \& Huang, R. H. Molecular mechanisms of the CdnG-Cap5 antiphage defense system employing 3', 2'-cGAMP as the second messenger. Nature Communications (2021).

37. Jiang, K. et al. Structural Basis of Formation of the Microtubule Minus-End-Regulating CAMSAP-Katanin Complex. Structure 26, 375-382.e4 (2018).

38. Saha, C. K., Sanches Pires, R., Brolin, H., Delannoy, M. \& Atkinson, G. C. FlaGs and webFlaGs: discovering novel biology through the analysis of gene neighbourhood conservation. Bioinformatics 37, 1312-1314 (2021).

39. Zimmermann, L. et al. A completely reimplemented MPI bioinformatics toolkit with a new HHpred server at its core. Journal of molecular biology 430, 2237-2243 (2018). 
601

602

603
40. Jumper, J. et al. Highly accurate protein structure prediction with AlphaFold. Nature 596, 583-589 (2021).

41. Holm, L. \& Rosenström, P. Dali server: conservation mapping in 3D. 38, W545-9 (2010).

42. Simanshu, D. K., Yamaguchi, Y., Park, J.-H., Inouye, M. \& Patel, D. J. Structural basis of mRNA recognition and cleavage by toxin MazF and its regulation by antitoxin MazE in Bacillus subtilis. Molecular cell 52, 447-458 (2013).

43. Pinti, M. et al. Emerging role of Lon protease as a master regulator of mitochondrial functions. Biochimica et Biophysica Acta (BBA)-Bioenergetics 1857, 1300-1306 (2016).

44. Rotanova, T. V. et al. Slicing a protease: structural features of the ATP $\square$ dependent Lon proteases gleaned from investigations of isolated domains. Protein Science 15, 18151828 (2006).

45. Lee, I. \& Suzuki, C. K. Functional mechanics of the ATP-dependent Lon proteaselessons from endogenous protein and synthetic peptide substrates. Biochimica et Biophysica Acta (BBA)-Proteins and Proteomics 1784, 727-735 (2008).

46. Shin, M. et al. Structural basis for distinct operational modes and protease activation in AAA+ protease Lon. Science advances 6, eaba8404 (2020).

47. Schifano, J. M. et al. tRNA is a new target for cleavage by a MazF toxin. Nucleic Acids Res 44, 1256-1270 (2016).

48. Zorzini, V. et al. Substrate Recognition and Activity Regulation of the Escherichia coli mRNA Endonuclease MazF. Journal of Biological Chemistry 291, 10950-10960 (2016).

49. Culviner, P. H. \& Laub, M. T. Global analysis of the E. coli toxin MazF reveals widespread cleavage of mRNA and the inhibition of rRNA maturation and ribosome biogenesis. Molecular cell 70, 868-880. e10 (2018).

50. Schuster, C. F. \& Bertram, R. Toxin-antitoxin systems are ubiquitous and versatile modulators of prokaryotic cell fate. FEMS microbiology letters 340, 73-85 (2013).

51. van Beljouw, S. P. B. et al. The gRAMP CRISPR-Cas effector is an RNA endonuclease complexed with a caspase-like peptidase. Science (2021).

52. Liu, H. \& Naismith, J. H. An efficient one-step site-directed deletion, insertion, single and multiple-site plasmid mutagenesis protocol. BMC Biotechnology 8, 91 (2008).

53. Cianci, M. et al. P13, the EMBL macromolecular crystallography beamline at the lowemittance PETRA III ring for high-and low-energy phasing with variable beam focusing. Journal of synchrotron radiation 24, 323-332 (2017).

54. Kabsch, W. Automatic-Indexing of Rotation Diffraction Patterns. 21, 67-71 (1988).

55. Liebschner, D. et al. Macromolecular structure determination using X-rays, neutrons and electrons: recent developments in Phenix. Acta Crystallographica Section D: Structural Biology 75, 861-877 (2019).

56. Emsley, P. \& Cowtan, K. Coot: model-building tools for molecular graphics. Acta Crystallographica Section D 60, 2126-2132 (2004).

57. Williams, C. J. et al. MolProbity: More and better reference data for improved all $\square$ atom structure validation. Protein Science 27, 293-315 (2018).

58. Robert, X. \& Gouet, P. Deciphering key features in protein structures with the new ENDscript server. Nucleic acids research 42, W320-W324 (2014).

59. Simanshu, D. K., Yamaguchi, Y., Park, J.-H., Inouye, M. \& Patel, D. J. Structural basis of mRNA recognition and cleavage by toxin MazF and its regulation by antitoxin MazE in Bacillus subtilis. Molecular cell 52, 447-458 (2013). 
bioRxiv preprint doi: https://doi.org/10.1101/2021.12.06.471393; this version posted December 6, 2021. The copyright holder for this preprint (which was not certified by peer review) is the author/funder. All rights reserved. No reuse allowed without permission.

604 Supplemental Table 1: Data collection and refinement statistics

\begin{tabular}{|c|c|}
\hline Wavelength $(\AA)$ & 0.9795 \\
\hline Resolution range $(\AA)$ & $54.06-2.1(2.175-2.1)$ \\
\hline Space group & $\mathrm{P} 3221$ \\
\hline Unit cell $\left(\AA{ }^{\circ},{ }^{\circ}\right)$ & $68.90,68.90,255.38,90,90,120$ \\
\hline Total reflections & $83686(7464)$ \\
\hline Unique reflections & $41843(3732)$ \\
\hline Multiplicity & $2.0(2.0)$ \\
\hline Completeness (\%) & $99.02(90.28)$ \\
\hline $\mathrm{I} / \operatorname{sigma}(\mathrm{I})$ & $23.20(2.36)$ \\
\hline Wilson B-factor $\left(\AA^{2}\right)$ & 36.42 \\
\hline R-merge & $0.054(0.3444)$ \\
\hline R-meas & $0.07637(0.4871)$ \\
\hline R-pim & $0.054(0.3444)$ \\
\hline $\mathrm{CC} 1 / 2$ & $0.995(0.705)$ \\
\hline $\mathrm{CC}^{*}$ & $0.999(0.909)$ \\
\hline Reflections used in Refinement & $41842(3732)$ \\
\hline Reflections used for R-free & $1996(175)$ \\
\hline R-work & $0.1932(0.2489)$ \\
\hline R-free & $0.2255(0.3097)$ \\
\hline CC(work) & $0.962(0.818)$ \\
\hline $\mathrm{CC}($ free $)$ & $0.941(0.741)$ \\
\hline Number of non-hydrogen atoms & 4487 \\
\hline Ramachandran outliers/favored (\%) & $(0 / 97)$ \\
\hline Clashscore & 4.53 \\
\hline Molprobity score & 1.43 \\
\hline Macromolecules & 4175 \\
\hline Ligands & 69 \\
\hline Solvent & 243 \\
\hline
\end{tabular}

605 Numbers in parenthesis refer to the shell of highest resolution. 
607 Supplemental Table 2: Substrate for the ribonuclease assay

\begin{tabular}{llc}
\hline Name & Sequence & Bases \\
\hline RNA A & 5'-FAM-UGCUAAUCUACUAUAGAAUUGAAAG & 25 \\
RNA B & 5'-FAM-UGAUAAUCUCUUAUAGA & 17 \\
& 5'-6-FAM ${ }^{\text {TM_ }}$ & 37 \\
RNA C & UGUCGUCAGACCCAAAACCCCGAGAGGGGACGGAAAC & \\
& 5'-FAM- & 60 \\
RNA D & AUUGAAAGACCAUACCCAACUUCUAACAACGUCGUUCUUAAC & 6 \\
& AACGGAUUAAUCCCAAAA & \\
RNA E & 5'--FAM-AUGUAGAUGUAUUCCAGUAUAAUAAGGAUUAAGAC & 35 \\
\hline
\end{tabular}

608

609 


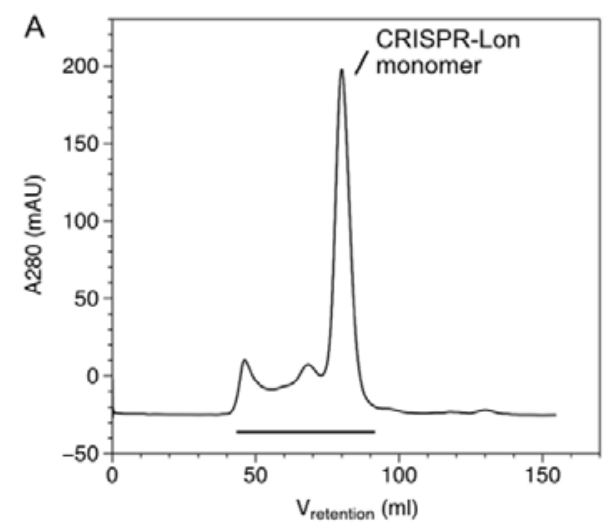

B

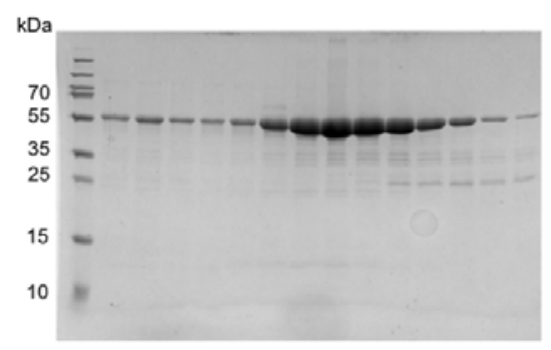

610

611 Supplemental Figure 1: Purification of CRISPR-Lon. A) Gelfiltration chromatography 612 (Superdex 200 16/60) of CRISPR-Lon. The protein elutes as a monomer. B) SDS-PAGE 613 analysis of the fractions indicated by the black bar in A).

614 
A

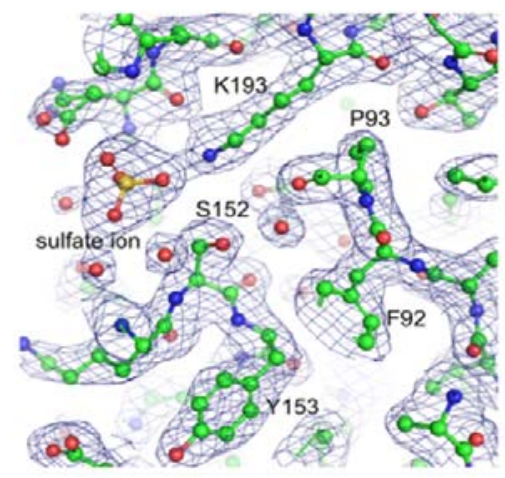

C

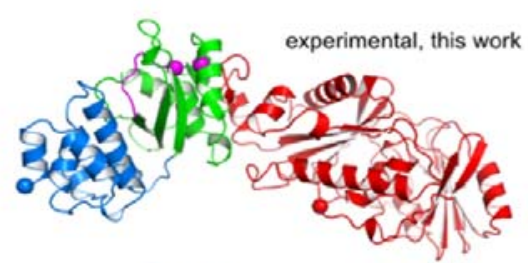

615

616

617

618

619

620

621

622
B

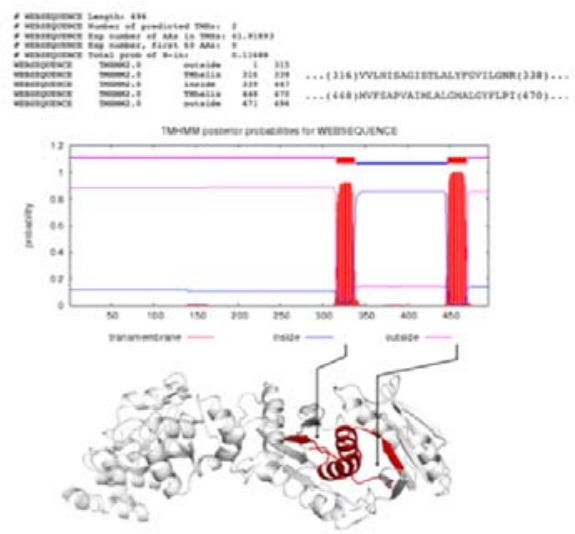

D

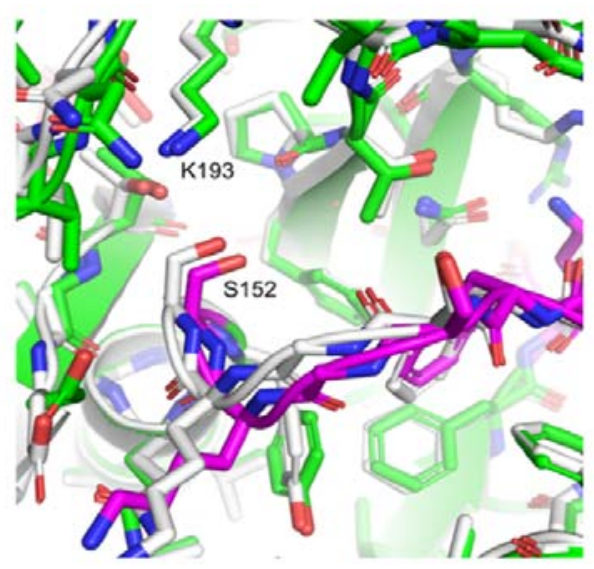

Supplemental Figure 2: Refinement and model building. A) Representative electron density of the SeMet CRISPR-Lon crystal structure. The structural model is shown in balland-stick representation. Selected residues are labeled. The blue mesh is a $2 \mathrm{mFo}-\mathrm{DFc}$ electron density map contoured at $1.0 \sigma$. B) TM-prediction by the TMHMM 2.0 server ${ }^{35} \mathrm{vs}$ experiment. C) Deepmind/alphafold2 vs experiment. D) Close-up of the Lon protease active site region with the catalytic dyad residues S152 and K193 labelled. 


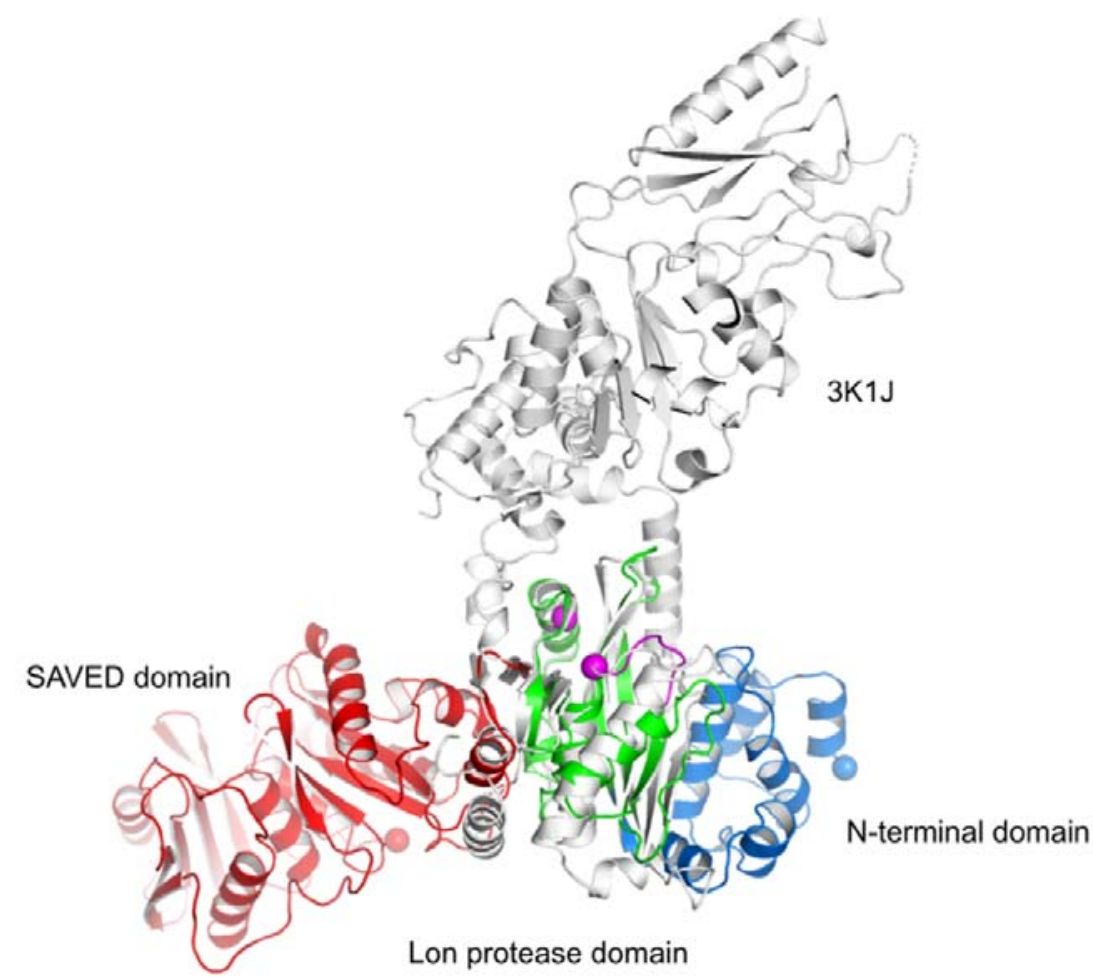

624 Supplemental Figure 3: Superposition of CRISPR-Lon active site with the ATP625 dependent Lon protease from Thermocuccus onnorineus. CRISPR-Lon is shown as a 626 cartoon model color-coded as in Figure 1. The Lon protease from T. onnorineus (PDB-ID: 627 3K1J, DALI Z-score: $\left.12.8,{ }^{31}\right)$ is shown as a white cartoon model.

628 

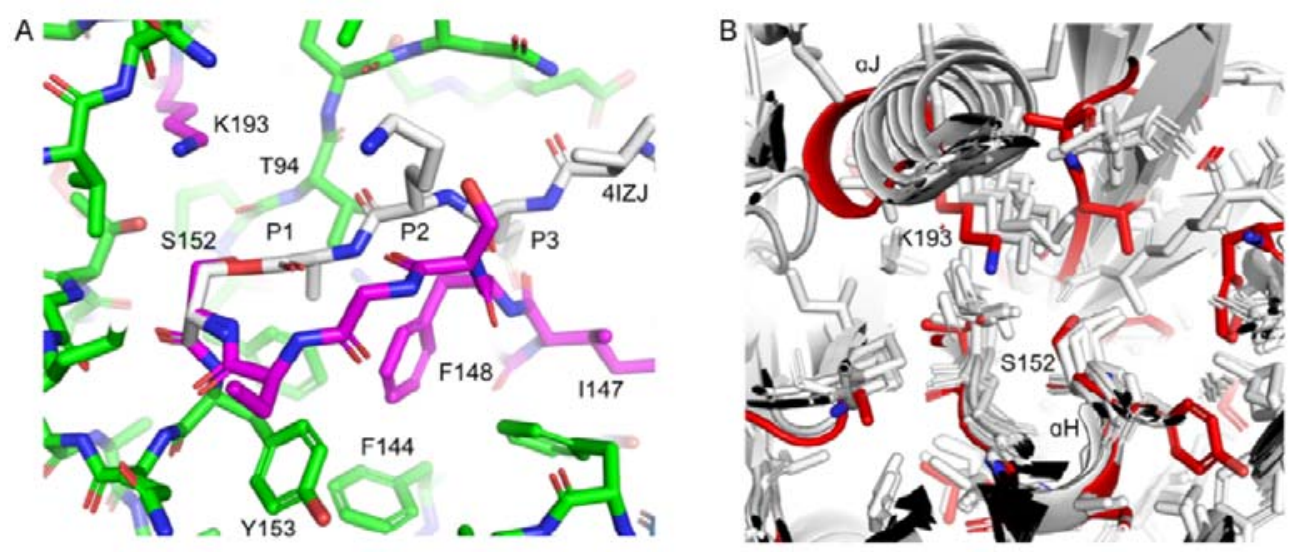

630 Supplemental Figure 4: A) Superposition of CRISPR-Lon active site with the acylenzyme intermediate of yellowfin asciitis virus protease. A) CRISPR-Lon is shown in sticks representation and color-coded as in Figure 1. Chain D of structure 4IZJ ${ }^{34}$ (residues 630-640) was superimposed on the corresponding residues of CRISPR-Lon (150-160) leading 634 to an r. m. s. d. of $0.314 \AA$. Of 4IZJ, only the acyl-enzyme intermediate is shown in sticks 635 mode. Selected residues and the positions of the P1-P3 sites are indicated. B) Comparison of 636 the CRISPR-Lon (red) protease active site with related structures (white). The structures were superposed based on the catalytic serines and the $\square$-helices immediately downstream of it

638

639 

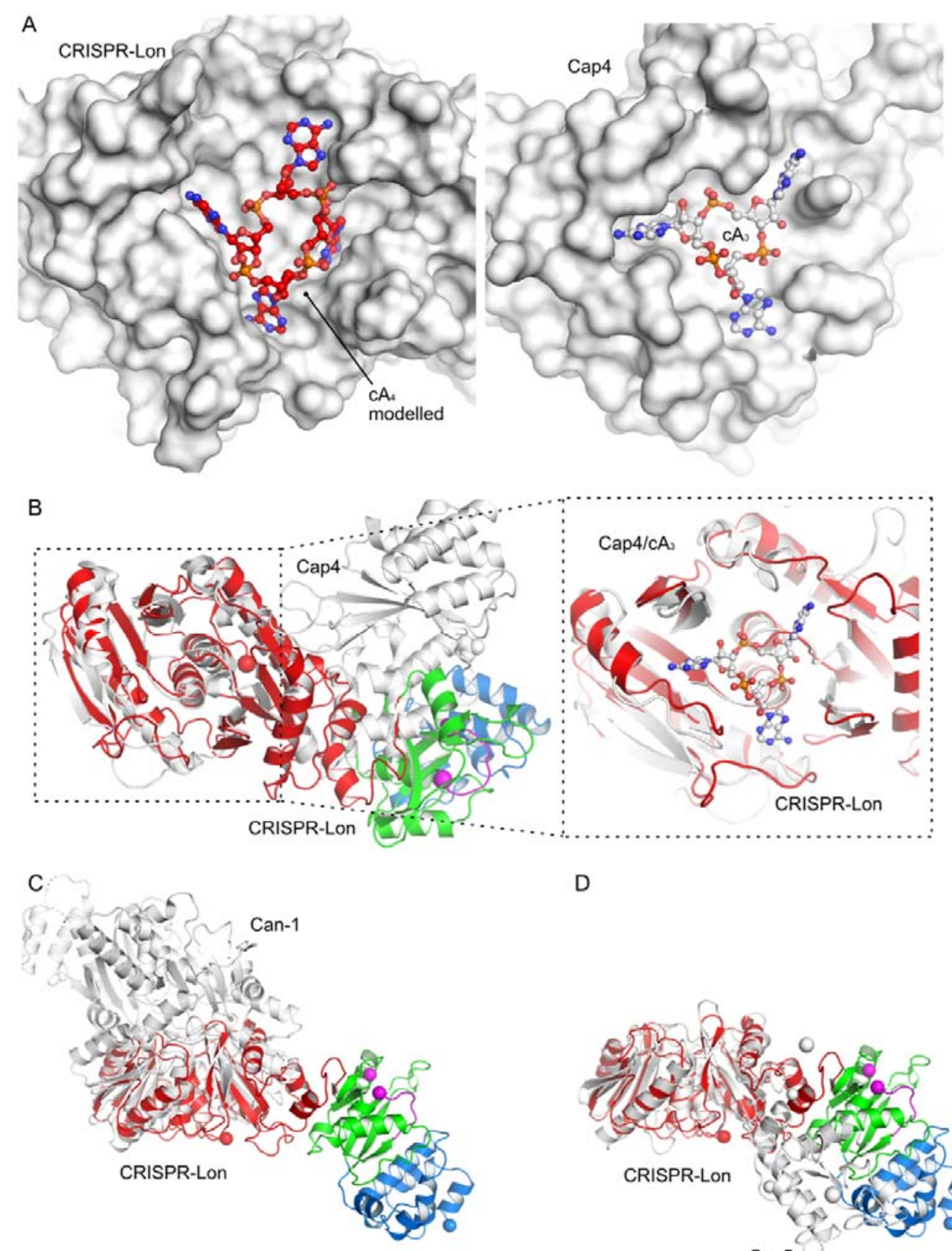

D

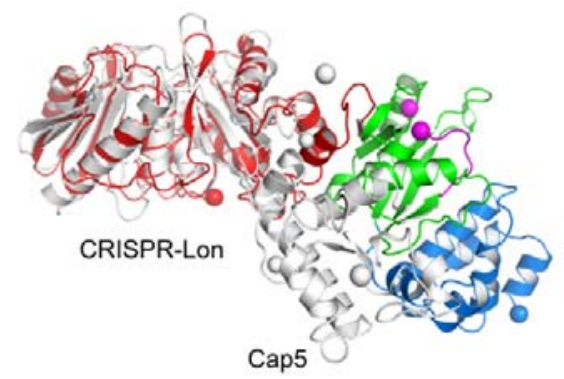

641 Supplemental Figure 5: The SAVED domain of CRISPR-Lon. A) Left: A cA molecule $_{4}$ 642 (red balls-and-sticks) was modeled into the cOA binding site of the CRISPR-Lon SAVED 643 domain (white surface). Right: The Cap4/cA 3 complex structure. The $\mathrm{cA}_{3}$ molecule is shown 644 as white balls-and-sticks and Cap4 as a white surface (PDB-ID: 6VM6 ${ }^{24}$ ). Both CRISPR-Lon 645 and Cap4 are oriented as in B). B) Left: Superposition of CRISPR-Lon (color scheme as in 646 Figure 1) with the Cap4 protein (white, PDB-ID: 6VM6 ${ }^{24}$ ). Right: Close-up of the 647 superposed SAVED domains. The $\mathrm{cA}_{3}$ molecule of the Cap4 complex structure is shown as 648 white ball-and-stick model (PDB-ID: 6WAN ${ }^{24}$ ). C) Superposition of the CRISPR-Lon 649 SAVED domain (color scheme as in Figure 1) with the CARF domains of the Can1 protein 650 (white, PDB-ID: 6SCE ${ }^{19}$ ). D) Superposition of the CRISPR-Lon SAVED domain (color 651 

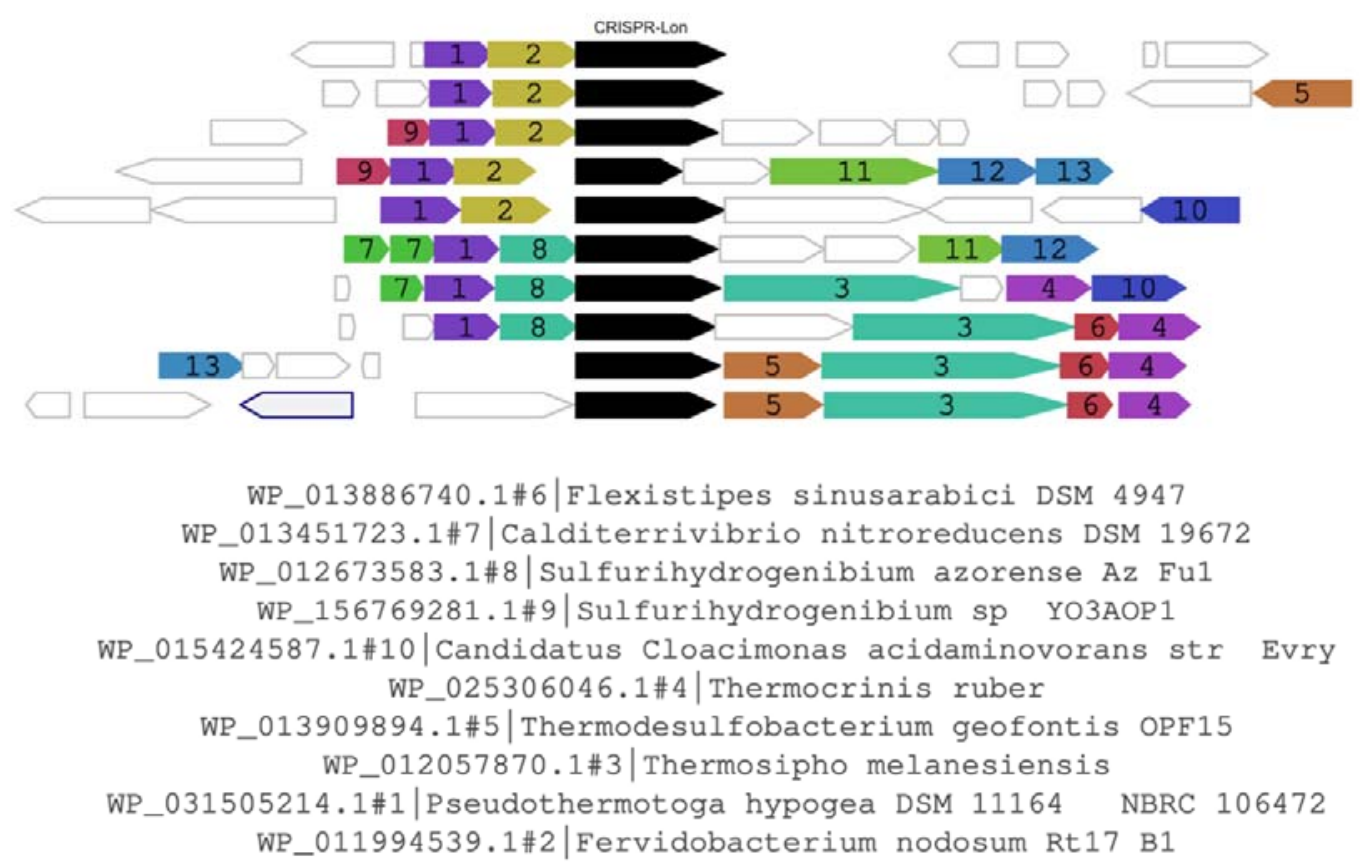

652

653 Supplemental Figure 6: Genetic neighborhood of CRISRP-Lon as determined by the 654 WebFLAGs ${ }^{38}$ server. The CRISPR-Lon gene is shown as a black arrow and the CRISPR-T 655 gene as a yellow arrow. Genes of a certain color have similar sequences that form numbered 656 groups. Genes without filling color are not conserved in the given context. Grey genes with 657 blue borders are pseudogenes. 


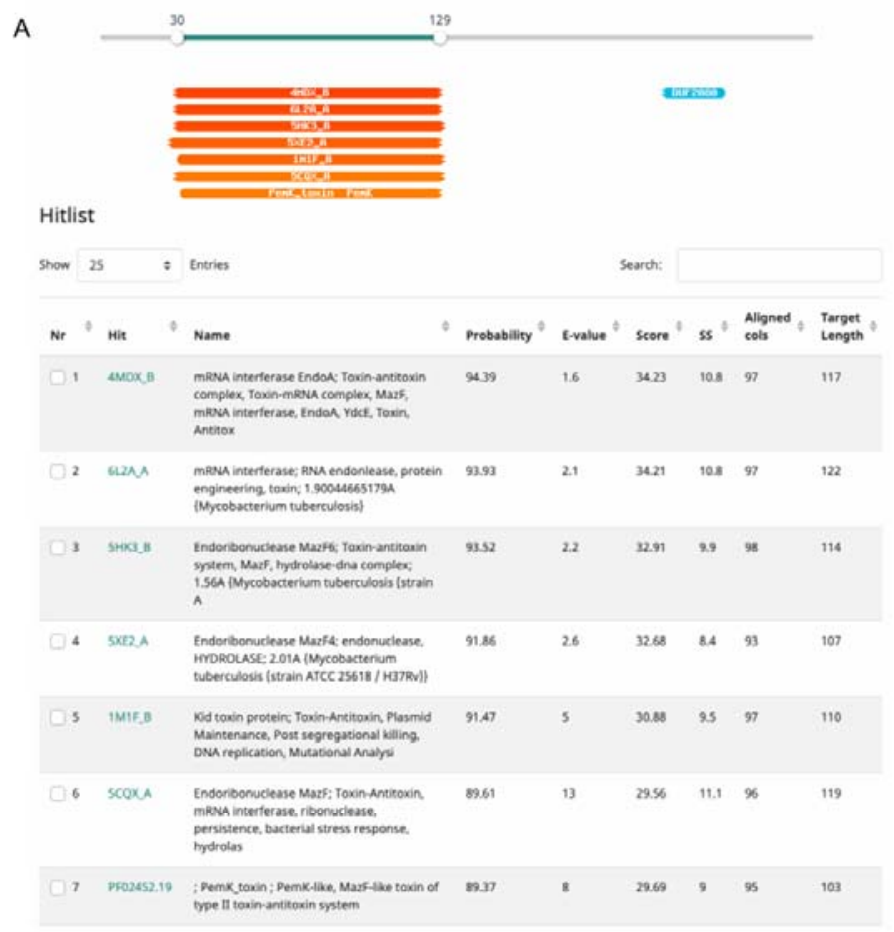

B

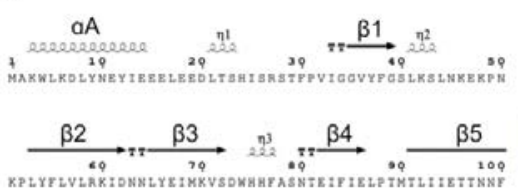

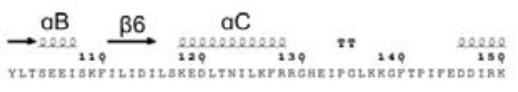

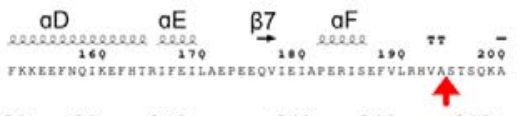

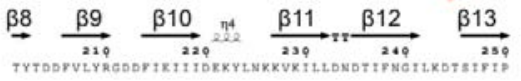

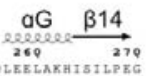

C

660 Supplemental Figure 7: Bioinformatic information about CRISPR-T. A) HHPred ${ }^{39}$ result 661 for CRISPR-T. B) Secondary structure of the predicted CRISPR-T (Figure 2B) structure 662 mapped to its amino acid sequence (ESPRIPT ${ }^{58}$ ). The CRISPR-Lon cleavage site is marked 663 with a red arrow. C) A superposition of the predicted CRISPR-T structure (compare Figure 664 2B) with the MazE/F (orange/yellow) complex and the MazF/ssRNA complex (only the RNA 665 is shown as spheres model) (PDB-IDs: 4ME7 ${ }^{59}$ and 5CR2 ${ }^{48}$ ). The deepmind/alphafold2 ${ }^{40}$ 666 prediction confidence is mapped onto the CRISPR-T structure. Note that the MazE/F complex 667 is dimeric and only one half of the full complex is shown for clarity. 
A

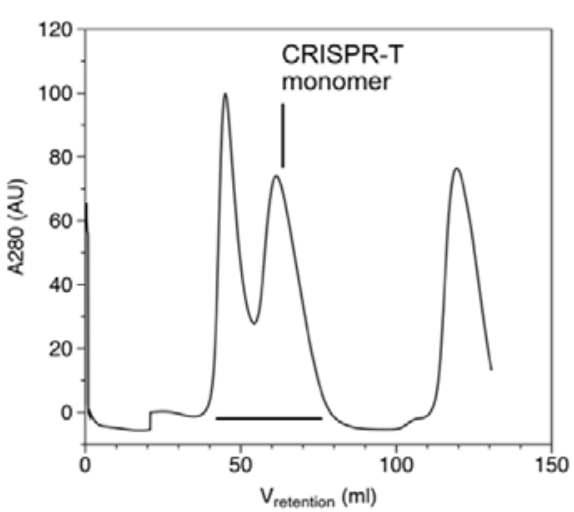

B

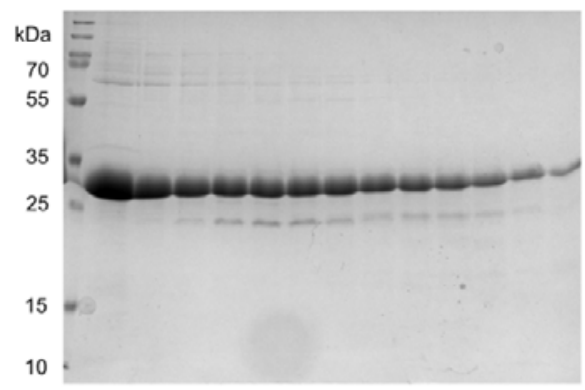

670 Supplemental Figure 8: Purification of CRISPR-T A) Gelfiltration chromatography 671 (Superdex 75 16/60) of CRISPR-T. The protein elutes as a monomer. B) SDS-PAGE analysis 672

673

674 

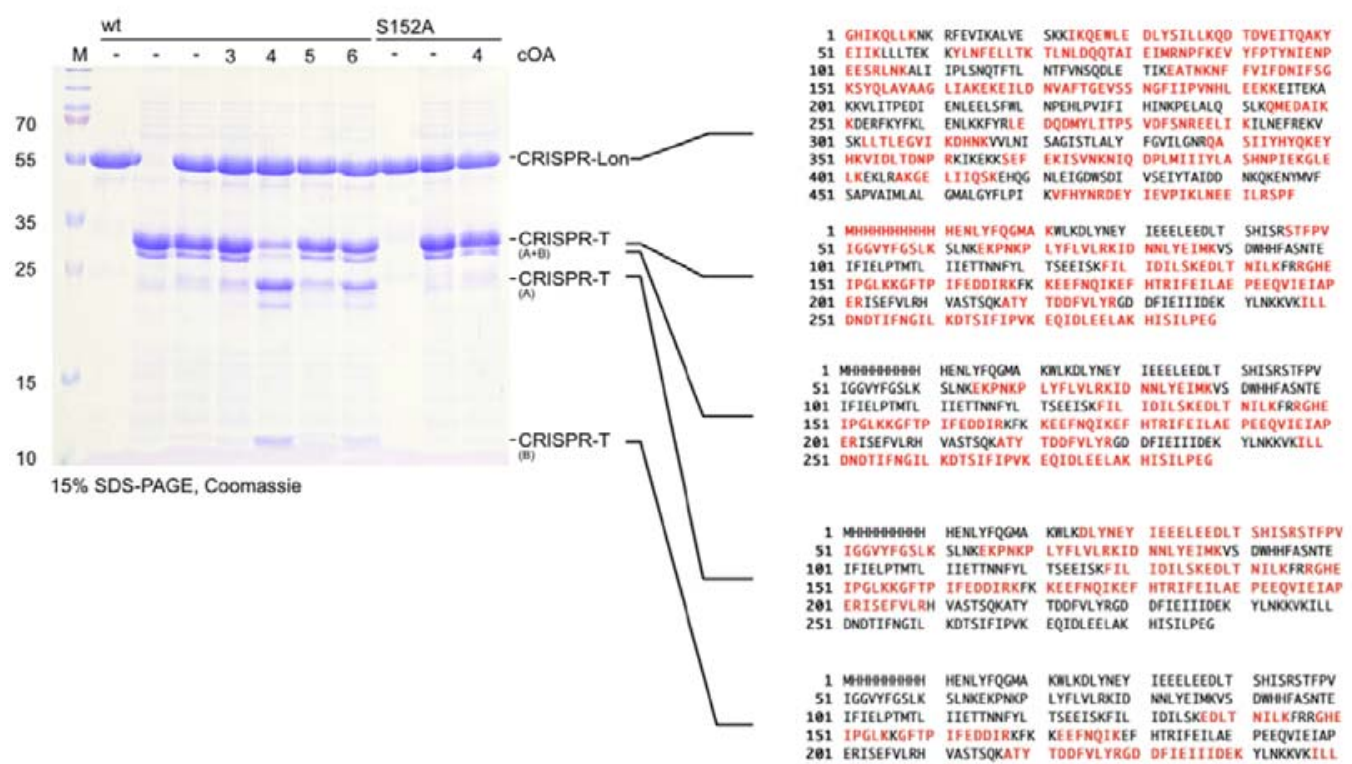

675

676

677

Supplemental Figure 9: Peptide fingerprints of cleavage bands. The indicated gel-bands

678 were cut from the gel and submitted for identification at the Mass spectrometry and

679 proteomics facility at the University of St Andrews (Fife, UK, https://mass-spec.wp.st-

680 andrews.ac.uk). Red letters indicate peptides that were identified in the respective sample.

681 
682

683

684

685

686

687

688

689

690

691

692

693

694

695

696

697

698

699

700

701

702

703
A

A SDS-PAGE

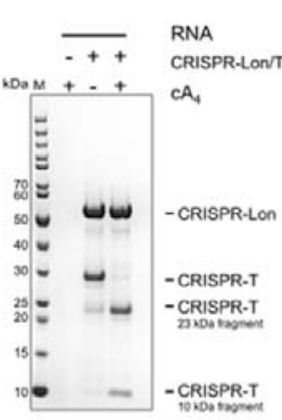

B
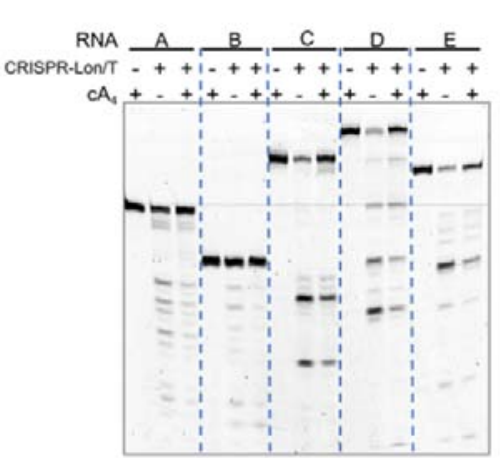

C

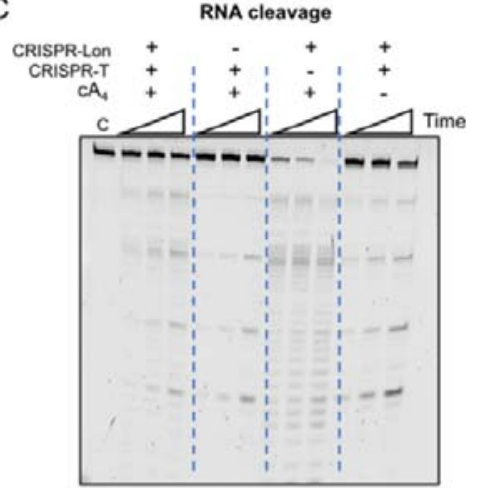

Supplemental Figure 10: Probing the RNase activity of the activated toxin. A) SDSPAGE analysis of $\mathrm{cA}_{4}$-induced cleavage of CRISPR-T (33 kDa) by CRISPR-Lon. Cleavage is complete after $60 \mathrm{~min}$ at $60{ }^{\circ} \mathrm{C}$. B) Fluorescence image of the denaturing polyacrylamide gel electrophoresis to determine ribonuclease activity of the reactions shown in A) against five fluorescently-labelled RNA substrates (RNAs listed in Supplemental Table 2 correspond to set A, B, C, D and E). Some cleavage reactions were observed after $60 \mathrm{~min}$ incubation at 60 ${ }^{\circ} \mathrm{C}$, but these were not dependent on the presence of $\mathrm{cA}_{4}$ activator. C) Activity of CRISPRLon and CRISPR-T toward fluorescent-labelled RNA substrate D. Reaction mixture was incubating for 5,10 and $30 \mathrm{~min}$ at $60{ }^{\circ} \mathrm{C}$. Control reaction only contains the RNA substrate. The Lon protease degraded the RNA substrate, suggesting the presence of an RNase contaminant. The same banding pattern seen in B was observed when CRISPR-T was present, but this was not dependent on the presence of the protease or the $\mathrm{cA}_{4}$ activator. 